\title{
Respirasjonsforstyrrelser under søvn
}

\author{
Sammendrag \\ Bakgrunn. Pusteforstyrrelser under \\ $s ø v n$ (sleep related breathing dis- \\ orders, SRBD) er et samlebegrep som \\ omfatter flere diagnoser. Artikkelen \\ omhandler etiologi, diagnostikk, \\ behandlingsalternativer og konsekven- \\ ser av ubehandlet sykdom for både \\ barn og voksne.
}

Materiale og metode. Artikkelen er basert på litteratur fremskaffet ved et ikke-systematisk søk i PubMed, bøker og egen klinisk erfaring.

Resultater. Forekomsten av pusteforstyrrelser under søvn hos barn og voksne ligger på 10-15\%. Den alvorligste formen, obstruktiv søvnapné-syndrom (OSAS), har en forekomst på 2-4\%. Diagnosen pusteforstyrrelser under søvn stilles ved søvnunders $ø$ kelser. De kliniske symptomene hos voksne er kraftig snorking, observerte apneer, gisping etter luft med hyppig oppvåkning, urolig søvn og søvnighet på dagtid. Barn kan ofte reagere med hyperaktivitet og få lærings- og atferdsvansker. Ubehandlede pasienter har økt sykelighet og dødelighet. Første behandlingsalternativ for dem med middels til alvorlig grad av pusteforstyrrelser under søvn er kontinuerlig overtrykksventilasjon. Alternative behandlinger er bittskinner og kirurgisk behandling. Hos barn er kirurgi førstevalget (adenotonsillektomi).

Fortolkning. Diagnosen obstruktiv søvnapné-syndrom er den alvorligste av pusteforstyrrelsene. Både hos voksne og barn ser man nedsatt kognitiv funksjon og nedsatt livskvalitet. Det finnes ulike behandlingsalternativer.

\section{Harriet Akre}

harriet.akre@lds.no

Britt Øverland

$\emptyset$ re-nese-hals-avdelingen

Lovisenberg Diakonale Sykehus

0440 Oslo

Olav Skatvedt

Søvnspesialisten AS

Betegnelsen «respirasjonsforstyrrelser under søvn» (sleep related breathing disorders, SRBD) brukes for å beskrive apneer, redusert respirasjon (hypopneer) og andre pusteforstyrrelser under søvn. $2-4 \%$ av befolkningen har den alvorligste sykdommen, kalt obstruktiv søvnapné-syndrom (OSAS) (1), mens så mange som $10-15 \%$ har mildere former for respirasjonsforstyrrelser under søvn (2). Det er også rimelig å anta at flere etter hvert vil få denne diagnosen, da det er en sterk sammenheng med overvekt (3) og dette er et økende problem i Norge. Det er også en vanlig sykdom hos barn (2-3\%) $(4,5)$, med alvorlige konsekvenser for læring og kognitiv utvikling.

\section{Materiale og metode}

Arbeidet er basert på litteratur fremskaffet fra et ikke-systematisk søk i PubMed, bøker og egen klinisk erfaring.

\section{Patofysiologi}

Respirasjonsforstyrrelser under søvn kan blant annet skyldes anatomisk trange øvre luftveier forårsaket av for mye bløtvev, som lang, ødematøs og injisert bløt gane og store tonsiller, stor tunge og tilbaketrukket eller liten underkjeve. Trange øvre luftveier gir $ø \mathrm{kt}$ luftveismotstand. Dette gir igjen økt negativt trykk i de øvre luftveier ved inspirasjon og dermed kollaps. Alternativt vil inadekvat dilaterende muskelaktivitet også gi kollaps av de øvre luftveier. Barn med Downs syndrom (6) og barn med kraniofaciale deformiteter (7) har trange øvre luftveier og nedsatt muskeltonus.

\section{Kliniske symptomer}

De kliniske symptomene på pusteforstyrrelser under søvn er kraftig snorking om natten, uregelmessig pust, observerte apneer, gisping etter luft med hyppig oppvåkning og urolig søvn. Mange klager over at de er slitne om morgenen, og ofte er de mer slitne og søvnige når de står opp om morgenen enn når de legger seg om kvelden. Mange våkner med hodepine. Barn kan reagere med hyperaktivitet på dagtid, men også med søvnighet om dagen. I uttalte tilfeller hos barn ser man vektreduksjon og dårlig trivsel. Overvekt er vanlig hos voksne med pusteforstyrrelser under søvn, men mange er også normalvektige.

Noen av hovedsymptomene på pusteforstyrrelser under søvn er søvnighet om dagen, nedsatt livskvalitet, angst og depresjon. Imidlertid er ingen av disse symptomene nok til å stille diagnosen, fordi det kliniske bildet i liten grad stemmer overens med resultater av standardiserte søvnundersøkelser. Dessuten er det vanskelig å fastsette alvorlighetsgraden.

\section{Diagnostikk}

Diagnosen stilles ved søvnundersøkelser. Både hos barn og voksne er polysomnografi (PSG) gullstandarden $(7,8)$. Ved PSG-undersøkelse måler man søvn og søvnkvalitet samtidig med luftstrøm, bevegelse av thorax og abdomen, hjerteaktivitet og oksygenmetning. Hos barn er ofte samtidig videoovervåking nødvendig for å stille diagnosen, hos voksne kan man også komme til målet med enklere målemetoder, kalt kardiorespiratoriske målinger. Ved polysomnografi registreres antall apneer og hypopneer, med påfølgende fall i oksygenmetningen, eller perioder med økt negativt luftveistrykk, som gir oppvåkning, per time pasienten sover. Dette gir en apné-hypopné-indeks (AHI) eller «respiratory disturbance index» (RDI). En $\mathrm{AHI} / \mathrm{RDI}$-verdi $>5$ hos voksne regnes som patologisk, mens det bare kreves en AHIverdi $>1$ hos barn for å stille SRBD-diagnosen. Har pasienten en AHI-verdi $\geq 30$, har vedkommende en alvorlig grad av respirasjonsforstyrrelser under søvn. Hos barn regnes en AHI-verdi $>10$ som alvorlig (tab 1).

Ved søvnundersøkelser ser man ofte en kortvarig oppvåkning etter pusteforstyrrelsene, før pusten igjen normaliseres. Noen kan således våkne mer enn 30 ganger i timen og får dermed en forstyrret søvn. Figur 1 viser søvnregistrering ved en obstruktiv apné som fører til oppvåkning. Pusteforstyr-

\section{Hovedbudskap}

- Søvnrelatert pustebesvær er en vanlig forekommende kronisk lidelse hos barn og voksne

- Lidelsen kan gi alvorlige symptomer

- For mange finnes det effektiv behandling 
relsene kan i uttalte tilfeller hindre at pasientene når dyp søvn eller gjøre at de får sterkt redusert REM-søvn.

\section{Komplikasjoner}

Pusteforstyrrelsene under søvn fører til fall i oksygenmetningen, noe som vil sette i gang mange kaskadereaksjoner på cellenivå, øke katekolaminnivået i blodet, øke blodtrykket samt føre til fragmentering av søvnen. Flere populasjonsstudier har vist at det er en sammenheng mellom pusteforstyrrelser under søvn og hjerte- og karsykdommer, inkludert høyt blodtrykk, koronar hjertesykdom og hjertesvikt (9). Det ser også ut til at selv milde former for pusteforstyrrelser under søvn gir økt risiko for kardiovaskulær sykdom (10).

Longitudinelle studier viser at jo høyere RDI-verdi, desto større er risikoen for utvikling av forhøyet arterielt blodtrykk, og at obstruktiv søvnapné og -hypopné er en uavhengig risikofaktor for å utvikle kardiovaskulær sykdom hos middelaldrende menn (11). Det er en signifikant høyere mortalitetsrisiko (HR (Hazard Risk) 3,8 (95\% KI 1,6-9,0)) for personer med ubehandlet pusteforstyrrelse under søvn og dagtretthet (12). Hos barn som snorker, har man påvist signifikant høyere blodtrykk (13) samt hypertrofi av venstre hjerteventrikkel (14).

Uavhengig av fedme er obstruktiv søvnapné-syndrom assosiert med insulinresistens og diabetes mellitus type 2. Det er også vist at den nedsatte insulinsensitiviteten bedres etter kontinuerlig overtrykksbehandling (15).

Økende grad av pusteforstyrrelser under søvn gir mer alvorlige konsekvenser på dagtid, som innlæringsproblemer, konsentrasjonsproblemer, hukommelsesproblemer og nedsatt oppmerksomhet. Dette kan være alvorlig ved f.eks. bilkjøring. Studier har vist at pasienter som har søvnapnésyndrom, er seks ganger mer utsatt for å være involvert i bilulykker enn friske kontrollpersoner, og søvnapnésyndrom er den vanligste årsaken til tendensen til å døse av under bilkjøring (16). Disse personene er også mer utsatt for arbeidsulykker. Pusteforstyrrelser under søvn er assosiert med økt sykefravær og økt risiko for å bli ufør (17), og mange har nedsatt livskvalitet. Selv dem med mild alvorlighetsgrad av obstruktiv søvnapné-syndrom kan ha problemer med å utføre daglige gjøremål (18). Hos barn kan dette gi seg utslag i atferds- og læringsvansker, med mulige vevsskader i hippocampus og frontal cortex $(19,20)$.

Mennesker med søvnapnésyndrom har symptomer lenge før de blir diagnostisert og behandlet. De bruker flere helsetjenester og har i gjennomsnitt dobbelt så mange liggedøgn i sykehus som kontrollgruppen, kontrollert for alder og kjønn (21). De som ble behandlet med kontinuerlig overtrykk, hadde signifikant færre døgn i sykehus og mindre bruk av andre helsetjenester, som kontakt med lege (22). Hos barn ser man det samme. Barn
Tabell 1 Inndeling av alvorlighetsgrad av respirasjonsforstyrrelser under søvn (sleep related breathing disorders, SRBD) ut fra polysomnografifunn hos barn og voksne. AHI-verdi lapnéhypopné-indeks) er antall apneer eller hypopneer per time søvn
Mild grad av respirasjonsforstyrrelser under søvn Moderat grad av respirasjonsforstyrrelser under søvn Alvorlig grad av respirasjonsforstyrrelser under søvn

$\begin{array}{cc}\text { Barn } & \text { Voksne } \\ A H I>1 & A H I>5 \\ A H I>5 & A H I>15 \\ A H I>10 & A H I>30\end{array}$

med obstruktiv søvnapné-syndrom hadde $2-3$ ganger økt bruk av helsetjenester (23) - flere turer til akuttmottak, flere sykehusinnleggelser og mer bruk av medikamenter.

\section{Behandling}

Kontinuerlig overtrykksbehandling

Anbefalt behandlingsalternativ for voksne med pusteforstyrrelser under søvn av middels til alvorlig grad er kontinuerlig overtrykksbehandling. Behandlingen virker på den måten at luftveiene holdes oppe ved hjelp av et lufttrykk. Hvor stort lufttrykk pasienten trenger, er individuelt og må tilpasses den enkelte. Pasienten får luften gjennom en maske som dekker nesen, eller både nese og munn, via en slange som er koblet til en maskin som generer lufttrykket. Det er særlig viktig å finne riktig maske, tilpasset pasientens individuelle ansiktsform, da varigheten av behandlingen er avhengig av om pasienten har en komfortabel maske. I tillegg er det en del som trenger luftfukting. Tiltak som endring av maske og luftfukting bør iverksettes så tidlig som mulig i utprøvningsfasen.

Størst innvirkning på hvor lenge pasientene fortsetter med behandlingen har vist seg å være hvordan de opplever tiltakene i den første tiden samt hvilken effekt de har på symptomene (24). Det har vært en stor utvikling av maskinene når det gjelder vekt, støy og pris. Dessverre er det ikke alle som kan eller vil bruke kontinuerlig overtrykk, og resultatene fra etterlevelsesstudier varierer. Mye tyder på at etter flere år er det $40-75 \%$ som fortsatt bruker maskinen (25, 26). Noen trenger mer kompliserte ikkeinvasive ventilatorer for å normalisere respirasjonsforstyrrelsene (27). Det er vist at kontinuerlig overtrykk gir mindre sykelighet og bedrer livskvaliteten $(28,29)$. Kontinuerlig overtrykk kan også være et godt behandlingsalternativ hos barn med pusteforstyrrelser under søvn som ikke responderer på kirurgi (fig 2) eller der kirurgi ikke er tilrådelig, f.eks. ved vekt under $10 \mathrm{~kg}$.

\section{Bittskinner}

Bittskinner er et behandlingsalternativ dersom pasienten ikke responderer på kontinuerlig overtrykksbehandling eller ved mildere grad av sykdommen. Bittskinner må skreddersys til den enkelte og krever som oftest tilpasning av en tannlege med kompetanse på området. Bittskinner er effektivt i

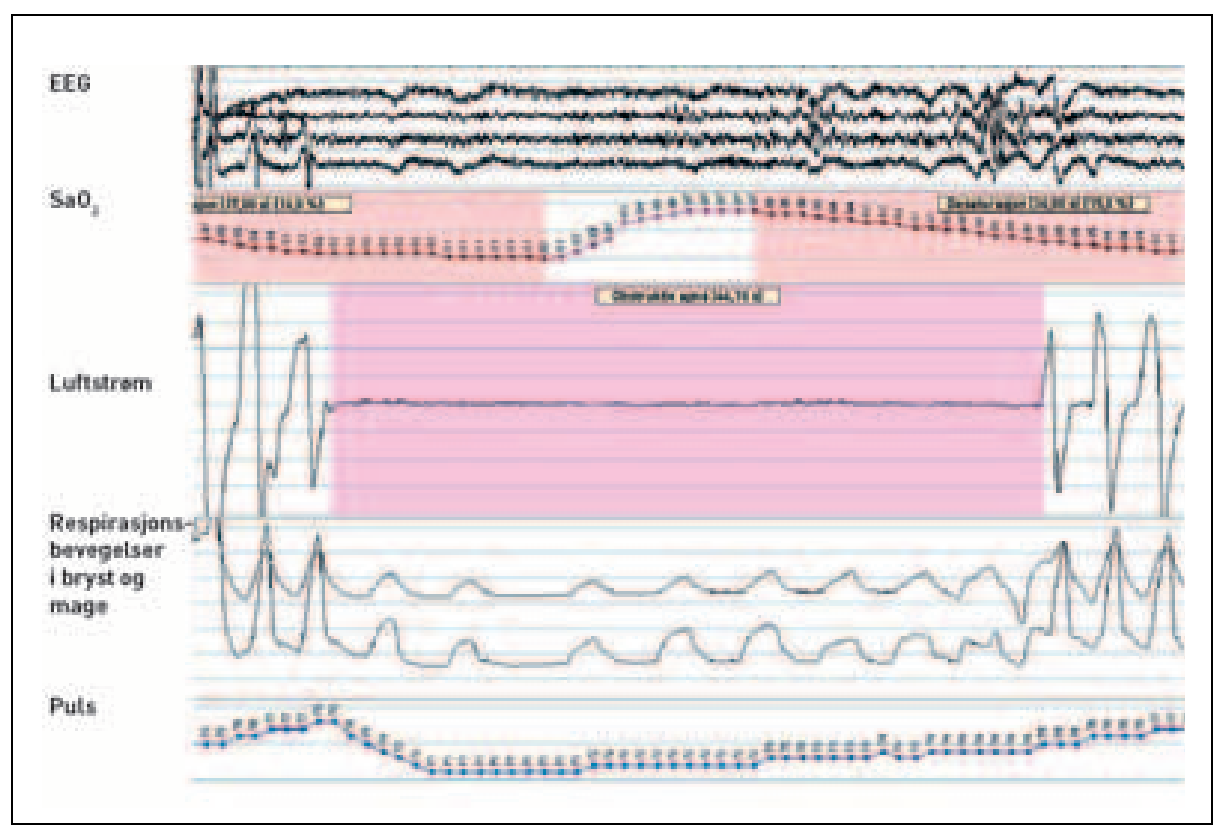

Figur 160 sekunder av en søvnregistrering. Det røde feltet viser en obstruktivapné. Pasienten fors øker å puste uten at det strømmer luft inn. Oksygenmetningen måles i fingeren og det tar tid før fallet registreres. Oksygenmetningen faller i begynnelsen av apneen pga. en tidligere apné og stiger til normale verdier for så å falle igjen ca. 30 sekunder etter at apneen begynte. Hjerneavledningene øverst viser at pasienten får en kort oppvåkning som avslutter apneen 


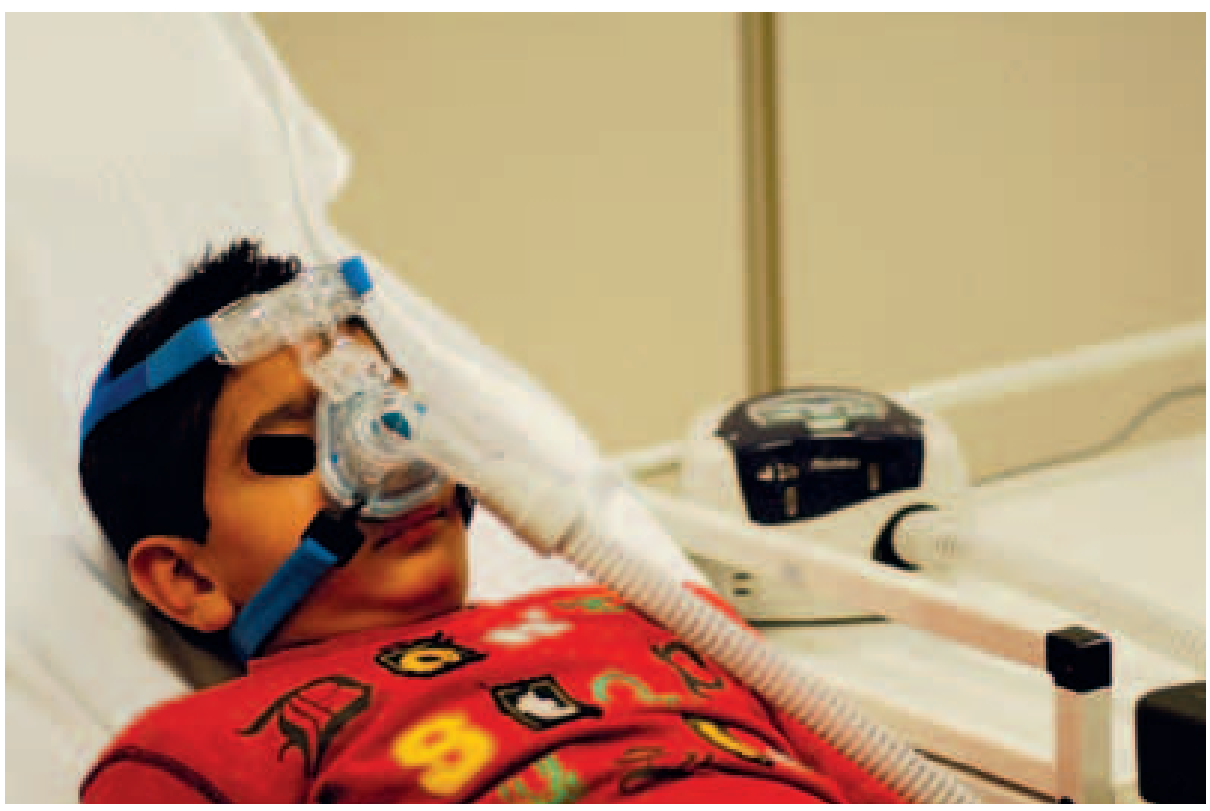

Figur 2 Sju år gammel gutt som får kontinuerlig overtrykksbehandling (continuos positive airway pres sure, CPAPI grunnet respirasjonsforstyrrelser under søvn. Han er tidligere tonsillektomert, uten tilstrekkelig effekt. Etter start av behandling har moren registrert bedre søvnkvalitet og skolen har bemerket forbedring i prestasjoner. Pasientens pårørende har gitt samtykke til at bildet blir publisert

behandling av respirasjonsforstyrrelser og har vist god effekt når det gjelder komplikasjoner av forstyrrelsen, som høyt blodtrykk (30). Ikke alle kan nyttiggjøre seg bittskinnebehandling, og mange klarer ikke å bruke bittskinner grunnet blant annet muskelsmerter og smerter fra kjeveleddet. Etterlevelsesdata har vist at $60-65 \%$ av dem som har fått tilpasset bittskinner, bruker dem (31).

Det er stor variasjon mellom de skandinaviske landene i bruk av bittskinner. Det antas å skyldes at man i Norge ikke refunderer denne type behandling, mens bruk av kontinuerlig overtrykksmaskin dekkes av det offentlige. Når det gjelder barn, er det for få undersøkelser til at man kan konkludere om denne behandlingen har effekt.

\section{Kirurgi}

Kirurgi er beste behandling for barn med pusteforstyrrelser under søvn. De vanligste prosedyrene er adenotomi eller adenotonsillektomi. Kirurgi er kurativt i de fleste av tilfellene hos barn (32), men det er særlig viktig å gjøre en postoperativ søvnundersøkelse av dem som fortsetter å snorke og sove urolig samt hos syndrombarn, som ofte trenger ytterligere behandling.

Hos voksne er kirurgi mer komplisert og noen typer inngrep mer kontroversielle. Mange trenger neseseptumplastikker, conchotomi og liknende for å kunne nyttiggjøre seg kontinuerlig overtrykksbehandling. Hos dem med mild til middels pusteforstyrrelser under søvn kan kirurgi i form av ganeplastikker med eller uten tonsillektomi være første behandlingsalternativ, særlig hvis pasienten har hypertrofiske ganetonsiller. Hos pasienter som ikke responderer eller ikke klarer å bruke kontinuerlig overtrykksmaskin eller bittskinner, er kirurgi et alternativ. Det kan i enkelte tilfeller også være aktuelt med ytterligere inngrep i form av fremflytting av mandibel og/eller maksille. Reduksjon av tungevolumet er det mange som har forsøkt, men resultatet av dette, særlig langtidsresultatet, er usikkert, og komplikasjonene kan være alvorlige (33). I ekstreme tilfeller må man av og til trakeotomere pasienter for å komme forbi trange eller ettergivelige øvre luftveier (34). Dette er særlig aktuelt hos nyfødte og små barn med store respirasjonsproblemer.

Kirurgi har vært kritisert av mange fordi det har vært rapportert manglende effekt, mange komplikasjoner og langtidsbivirkninger $\mathrm{i}$ form av svelgevansker og fremmedlegemefølelse i svelget. Flere store materialer viser imidlertid at morbiditeten og mortaliteten er lav (35). Det er viktig å selektere dem som kan ha nytte av et kirurgisk inngrep (36). Langtidseffekten kan også være vanskelig å måle fordi pusteforstyrrelser under søvn forverrer seg med økende alder, i tillegg til at mange øker i vekt, noe som i seg selv forverrer tilstanden.

I juni 2007 ble det utgitt en nordisk rapport hvor man hadde gått systematisk igjennom litteraturen som var publisert om søvnrelatert pustebesvær (37). Rapporten konkluderte med at ganeplastikker med eller uten fjerning av halsmandler ikke har effekt på tilstanden. Tvert imot hevdes det at inngrep av denne typen ikke bare er uvirksomme, men også svært farlige. Ifølge rapporten fikk $16 \%$ av pasientene alvorlige komplikasjoner under eller like etter inngrepet og $50-60 \%$ får varige langtidskomplikasjoner.

I rapporten har man kun inkludert prospektive, blindede studier. Man valgte å se bort fra flere tusen artikler som dokumenterer effekten av kirurgi - fordi forskningsmetodene ikke hadde høy nok kvalitet. Blin- ding er en studiestudiedesign som egner seg dårlig for kirurgisk forskning, fordi man under et inngrep ofte tar bort vev og det ikke er mulig å blinde dette for pasienten. Konklusjonene i denne rapporten når det gjelder kirurgisk behandling av respirasjonsforstyrrelser under søvn er omdiskutert innen ørenese-hals-faget, siden mange kirurger har god erfaring med denne type behandling og ser få alvorlige komplikasjoner.

\section{Livsstil}

Konservativ behandling i form av livsstilsendringer som røykeslutt og vektreduksjon er viktig (3). Mange pasienter er imidlertid så slitne og søvnige på dagtid at de ikke klarer å være mer fysisk aktive for å gå ned i vekt. Medikamentell behandling har foreløpig ingen plass i behandlingen av pusteforstyrrelser under søvn - utover behandling av allergier og liknende som virker inn på slimhinnene i de øvre luftveier. Sideleie kan ved stillingsindusert søvnapné ha god effekt, det samme kan hevet hodeende. Problemet er imidlertid å finne gode metoder som gjør at pasienten ligger mesteparten av tiden i den ønskede stilling.

\section{Hvem bør undersøkes}

Hos alle barn som sover urolig, bør man spørre pårørende om barnet snorker. Dersom barnet snorker kraftig om natten, sliter med å puste og sover urolig, bør man henvise til øre-nese-hals-spesialist. Man bør være spesielt oppmerksom på pusteforstyrrelser under søvn hos barn med kraniofaciale lidelser, Downs syndrom eller nevromuskulære lidelser. Voksne som snorker kraftig om natten og samtidig er søvnige på dagtid, bør henvises til søvnundersøkelse ved et søvnlaboratorium. Videre bør man hos pasienter med alvorlig overvekt, hjerte- og karlidelser eller nattlig høyt blodtrykk og diabetes spørre om symptomer på pusteforstyrrelser under søvn.

\section{Konklusjon}

Pusteforstyrrelser under søvn er en vanlig kronisk lidelse både hos barn og voksne. Den kan få store helsemessige konsekvenser på det individuelle plan. Også samfunnsmessig har pusteforstyrrelser betydning, fordi disse pasientene er storforbrukere av helsetjenester. I de aller fleste tilfellene har man god behandling å tilby, og pasientene vil som oftest umiddelbart merke stor klinisk effekt.

\section{Oppgitte interessekonflikter: Ingen}

\footnotetext{
Litteratur

1. Young T, Palta M, Dempsey J et al. The occurrence of sleep-disordered breathing among middle-aged adults. N Engl J Med 1993; 328: 1230-5.

Bixler EO, Vgontzas AN, Lin HM et al. Prevalence of sleep-disordered breathing in women: effects of gender. Am J Respir Crit Care Med 2001; 163: 608-13.

3. Peppard PE, Young T, Palta M et al. Longitudinal study of moderate weight change and sleepdisordered breathing. JAMA 2000; 284: 3015-21.
} 
4. Gislason T, Benediktsdottir B. Snoring, apneic episodes, and nocturnal hypoxemia among children 6 months to 6 years old. An epidemiologic study of lower limit of prevalence. Chest 1995; 107: 963-6.

5. Redline S, Tishler PV, Schluchter M. Risk factors for sleep-disordered breathing in children. Associations with obesity, race, and respiratory problems. Am J Respir Crit Care Med 1999; 159: 1527-32.

6. Marcus CL, Keens TG, Bautista DB et al. Obstructive sleep apnea in children with Down syndrome. Pediatrics 1991; 88: 132-9.

7. Ferraro N. Craniofacial development and the airway during sleep. I: Marcus CL, Carrol JL, Donnelly DF, red. Sleep and breathing in children. London: Informa healthcare, 2008: 293-309.

8. Iber C, Ancoli-Israel S, Chesson A et al. The AASM Manual for the scoring of sleep and associated events. Rules, terminology and technical specifications. Westchester, IL: American Academy of Sleep Medicine, 2007.

9. Nieto FJ, Young TB, Lind BK et al. Association of sleep-disordered breathing, sleep apnea, and hypertension in a large community-based study. Sleep Heart Health Study. JAMA 2000; 283: 1829-36.

10. Shahar E, Whitney CW, Redline S et al. Sleep-disordered breathing and cardiovascular disease: cross-sectional results of the Sleep Heart Health Study. Am J Respir Crit Care Med 2001; 163: 19-25.

11. Peker Y, Kraiczi H, Hedner J et al. An independent association between obstructive sleep apnoea and coronary artery disease. Eur Respir J 1999; 14: $179-84$

12. Young T, Finn L, Peppard PE et al. Sleep disordered breathing and mortality: eighteen-year followup of the Wisconsin sleep cohort. Sleep 2008; 31: $1071-8$.

13. Kwok KL, Ng DK, Cheung YF. BP and arterial distensibility in children with primary snoring. Chest 2003; 123: 1561-6.

14. Amin RS, Kimball TR, Bean JA et al. Left ventricular hypertrophy and abnormal ventricular geometry in children and adolescents with obstructive sleep apnea. Am J Respir Crit Care Med 2002; 165 . 1395-9.
15. Schahin SP, Nechanitzky T, Dittel C et al. Longterm improvement of insulin sensitivity during CPAP therapy in the obstructive sleep apnoea syndrome. Med Sci Monit 2008; 14: CR117-CR121.

16. Volna J, Sonka K. Medical factors of falling asleep behind the wheel. Prague Med Rep 2006; 107: $290-6$.

17. Sivertsen B, Øverland S, Glozier $N$ et al. The effect of OSAS on sick leave and work disability. Eur Respir J 2008; 32: 1497-503.

18. Baldwin CM, Griffith KA, Nieto FJ. The association of sleep-disordered breathing and sleep symptoms with quality of life in the Sleep Heart Health Study. Sleep 2001; 24: 96-105.

19. Halbower AC, Degaonkar M, Barker PB et al. Childhood obstructive sleep apnea associates with neuropsychological deficits and neuronal brain injury. PLoS Med 2006; 3: e301.

20. Hill CM, Hogan AM, Karmiloff-Smith A. To sleep, perchance to enrich learning? Arch Dis Child 2007; 92: 637-43.

21. Bahammam A, Delaive K, Ronald J et al. Health care utilization in males with obstructive sleep apnea syndrome two years after diagnosis and treatment. Sleep 1999; 22: 740-7.

22. Ronald J, Delaive K, Roos L et al. Health care utilization in the 10 years prior to diagnosis in obstructive sleep apnea syndrome patients. Sleep 1999; 22: 225-9

23. Reuveni H, Simon T, Tal A et al. Health care services utilization in children with obstructive sleep apnea syndrome. Pediatrics 2002; 110: 68-72.

24. Weaver TE, Grunstein RR. Adherence to continuous positive airway pressure therapy: the challenge to effective treatment. Proc Am Thorac Soc 2008; 5 : 173-8

25. Sin DD, Mayers I, Man GC, Pawluk L. Long-term compliance rates to continuous positive airway pressure in obstructive sleep apnea: a populationbased study. Chest 2002; 121: 430-5.

26. Pepin JL, Krieger J, Rodenstein D et al. Effective compliance during the first 3 months of continuous positive airway pressure. A European prospective study of 121 patients. Am J Respir Crit Care Med 1999; 160: 1124-9.

27. Schafer H, Ewig S, Hasper E. Failure of CPAP therapy in obstructive sleep apnoea syndrome: predictive factors and treatment with bilevel-positive airway pressure. Respir Med 1998; 92: 208-15. 28. Collop N. The effect of obstructive sleep apnea on chronic medical disorders. Cleve Clin J Med 2007. 74: $72-8$.

29. Somers VK, Dyken ME, Clary MP et al. Sympathetic neural mechanisms in obstructive sleep apnea. J Clin Invest 1995; 96: 1897-904.

30. Yoshida K. Effect on blood pressure of oral appliance therapy for sleep apnea syndrome. Int J Prosthodont 2006; 19: 61-6.

31. Gotsopoulos H, Chen C, Qian J et al. Oral appliance therapy improves symptoms in obstructive sleep apnea: a randomized, controlled trial. Am J Respir Crit Care Med 2002; 166: 743-8.

32. Goldstein NA, Fatima M, Campbell TF et al. Child behavior and quality of life before and after tonsillectomy and adenoidectomy. Arch Otolaryngol Head Neck Surg 2002; 128: 770-5.

33. Faye-Lund H, Djupesland G, Lyberg T. Glossopexia - evaluation of a new surgical method for treating obstructive sleep apnea syndrome. Acta Otolaryngol Suppl 1992; 492: 46-9.

34. Thatcher GW, Maisel RH. The long-term evaluation of tracheostomy in the management of severe obstructive sleep apnea. Laryngoscope 2003; 113 $201-4$.

35. Kezirian EJ, Weaver EM, Yueh B et al. Risk factors for serious complication after uvulopalatopharyngoplasty. Arch Otolaryngol Head Neck Surg 2006; 132: $1091-8$.

36. Tvinnereim M, Mitic S, Hansen RK. Plasma radiofrequency preceded by pressure recording enhances success for treating sleep-related breathing disorders. Laryngoscope 2007; 117: $731-6$.

37. Franklin K, Rehnqvist N, Axelsson S. Obstructive sleep apnoea syndrome. Report of a joint Nordic project. A systematic review. Stockholm: Statens beredning för medicinsk utvärdering, 2007.

Manuskriptet ble mottatt 11.11. 2008 og godkjent 2.7. 2009. Medisinsk redaktør Trine B. Haugen. 